\section{Response to: 'Detection of myositis-specific antibodies: additional notes' by Infantino et al}

We have with great interest read the response letter by Dr Infantino and colleagues on testing of methodologies used for detection of myositis-specific antibodies (MSA), to be published in the Annals of the Rheumatic Diseases. ${ }^{1}$ The authors discuss the need for validation of methodologies used for identifying MSA. The discussion stems from the publication of the new classification criteria for idiopathic inflammatory myopathies (IIM) '2017 European League Against Rheumatism/American College of Rheumatology classification criteria for adult and juvenile idiopathic inflammatory myopathies and their major subgroups' that include one MSA, the anti-Jo1 antibody. ${ }^{2}$

We agree with the authors that validation of the commercially available tests for MSA is of utmost importance and that this work should include all relevant stakeholders: clinicians, clinical laboratories actually performing the analyses as well as the diagnostic industry. We also believe that harmonisation and standardisation of actual assay implementation should be part of this discussion. Related to this, we also fully agree with Mahler and Fritzler $^{3}$ that the issue of internal antibody-specific controls and calibration of these assays should be addressed. Moreover, from a clinical point of view, we think that assay results should be interpreted in relation to longitudinally collected clinical data. The steering committee of the Euromyositis register has long been working on standardisation and systematic analyses of autoantibodies. Autoantibody data are recorded in the register (www.euromyositis.eu) along with clinical data, and will be an important source for a future update of classification criteria for IIM, as well as to increase our knowledge of associations between autoantibody positivity and clinical phenotype, disease progression and response to treatment. A prerequisite for the legitimacy of this work is the use of validated antibody assays. The line immunoassay has the advantage of being a fast and easy method that can be used routinely, but the new antibody specificities still need to be validated against immunoprecipitation and in relation to clinical cohorts with differential diagnoses. We therefore encourage all initiatives aimed at increasing our understanding of the role of MSA, as well as the accuracy of methods used for their detection. Inevitably, an international collaborative approach is needed. We believe that the Euromyositis register, including more than 5000 patients with IIM and involving 23 clinics worldwide, provides an appropriate foundation for this type of work, but will also need to include the manufacturers of the immunoassays in question.

We welcome collaborations with myositis experts in this work towards systematic and harmonised collection of autoantibody data in patients with IIM using validated immunoassays together with longitudinal clinical data.

Anna Tjärnlund, ${ }^{1}$ Ingrid E Lundberg, ${ }^{1}$ Johan Rönnelid ${ }^{2}$

${ }^{1}$ Rheumatology Unit, Department of Medicine, Karolinska University Hospital, Karolinska Institutet, Stockholm, Sweden

${ }^{2}$ Department of Immunology, Genetics and Pathology, Uppsala University, Uppsala, Sweden

Correspondence to Anna Tjärnlund, Rheumatology Unit, Department of Medicine, Karolinska University Hospital, Karolinska Institutet, Stockholm S-171 76, Sweden; anna.tjarnlund@ki.se

Handling editor Josef S Smolen

Competing interests None declared.

Patient consent Not required.

Provenance and peer review Commissioned; internally peer reviewed.

(c) Article author(s) (or their employer(s) unless otherwise stated in the text of the article) 2019. All rights reserved. No commercial use is permitted unless otherwise expressly granted.

\section{Check for updates}

To cite Tjärnlund A, Lundberg IE, Rönnelid J. Ann Rheum Dis 2019;78:e30.

Received 22 March 2018

Accepted 22 March 2018

Published Online First 3 April 2018

\section{SLinked}

- http://dx.doi.org/10.1136/annrheumdis-2018-213320

Ann Rheum Dis 2019;78:e30. doi:10.1136/annrheumdis-2018-213341

\section{REFERENCES}

1 Infantino M, Manfredi M, Grossi V, et al. Response to 'Detection of myositis-specific antibodies: additional notes'. Ann Rheum Dis 2019;78:e29.

2 Lundberg IE, Tjärnlund A, Bottai M, et al. 2017 European League Against Rheumatism/ American College of Rheumatology classification criteria for adult and juvenile idiopathic inflammatory myopathies and their major subgroups. Ann Rheum Dis 2017:76:1955-64.

3 Mahler M, Fritzler MJ. Detection of myositis-specific antibodies: additional notes. Ann Rheum Dis 2018:annrheumdis-2018-213153. 